\title{
Utilization of Fourier Transform Infrared Spectroscopy for Measurement of Organic Phosphorus and Bound Calcium in Cheddar Cheese
}

\author{
P. Upreti and L. E. Metzger ${ }^{1}$ \\ MN-SD Dairy Foods Research Center, Department of Food Science and Nutrition, University of Minnesota, St. Paul 55108
}

\begin{abstract}
The methods available for measuring organic $\mathrm{P}$ and bound $\mathrm{Ca}$ in cheese are either cumbersome or involve dilution of the cheese. Dilution of the cheese can lead to erroneous results, particularly in the case of bound Ca. Hence, the objective of this study was to evaluate the feasibility of Fourier transform infrared (FTIR) spectroscopy for direct measurement of organic $\mathrm{P}$ and bound Ca in Cheddar cheese. Two hundred sixteen samples of cheese were analyzed for protein-bound organic $\mathrm{P}$, bound Ca using a water-extraction based method, and buffering curves. Additionally, the infrared spectra of the cheeses were collected between 4,000 and 650 $\mathrm{cm}^{-1}$, at a resolution of $4 \mathrm{~cm}^{-1}$, and 256 scans per sample. The spectral shifts in the infrared region from 1,050 to $900 \mathrm{~cm}^{-1}$, in addition to the measured concentrations of organic $\mathrm{P}$, bound $\mathrm{Ca}$, and buffering peak area at $\mathrm{pH}$ 5.1, were used to develop calibration models using partial least squares (PLS) regression analysis. The spectral region of 956 to $946 \mathrm{~cm}^{-1}$ correlated with the measured concentrations of organic $\mathrm{P}$ and the overall PLS model had a correlation $\left(\mathrm{R}^{2}\right)$ of 0.76 between the predicted and measured concentrations. The spectral region at $\sim 980 \mathrm{~cm}^{-1}$ was correlated with the measured concentrations of bound $\mathrm{Ca}$, and the overall PLS model had a correlation $\left(\mathrm{R}^{2}\right)$ of 0.70 between the predicted and measured concentrations. A similar spectral region at $\sim 980 \mathrm{~cm}^{-1}$ was also correlated with the measured buffering peak areas and the overall PLS model had a correlation $\left(\mathrm{R}^{2}\right)$ of 0.64 between the predicted and measured peak areas. A linear regression analysis between the bound $\mathrm{Ca}$ and buffering peak area demonstrated that bound Ca was correlated $\left(R^{2}=0.73\right)$ with buffering peak area. This study demonstrates that FTIR can be used to measure organic $\mathrm{P}$ in cheeses. It also has the potential to be used for measuring bound $\mathrm{Ca}$ in undiluted cheeses, and for prediction of the buffering capacity of cheese.
\end{abstract}

Received October 17, 2005.

Accepted January 10, 2006.

${ }^{1}$ Corresponding author: lmetzger@umn.edu
Key words: calcium, phosphorus, Fourier transform infrared spectroscopy, buffering

\section{INTRODUCTION}

Calcium and phosphorus exist in different forms in Cheddar cheese. The portion of the $\mathrm{Ca}$ and $\mathrm{P}$ that is associated with the serum phase of cheese is referred to as soluble $\mathrm{Ca}$ and $\mathrm{P}$, whereas the portion that is associated with casein is called bound $\mathrm{Ca}$ and $\mathrm{P}$. Bound $\mathrm{P}$ in cheese can be further divided into 2 categories. The first category includes $\mathrm{P}$ that is covalently linked to the protein as phosphoserine residues, and is referred to as organic $\mathrm{P}$. The second category of bound $\mathrm{P}$ (referred to as bound-inorganic P), in addition to bound $\mathrm{Ca}$, constitute the inorganic constituents trapped in the structural network of casein (Schmidt, 1980). These inorganic constituents in caseins interact with phosphoserine residues of casein (organic $\mathrm{P}$ ) and act as a crosslinking agent within casein micelles (Aoki et al., 1987).

The importance of total $\mathrm{Ca}$ and $\mathrm{P}$ content in determining the texture and physicochemical characteristics (proteolysis, $\mathrm{pH}$ ) of cheese has been well recognized (Geurts et al., 1972; Lawrence et al., 1984; Kimura et al., 1992; Lucey and Fox, 1993; Metzger et al., 2001; Pastorino et al., 2003). However, as mentioned earlier, only a fraction of the total $\mathrm{Ca}$ and $\mathrm{P}$ (i.e., bound $\mathrm{Ca}$ and P) plays a role in cross-linking protein. Hence, studies based on this hypothesis have successfully demonstrated that distribution of $\mathrm{Ca}$ in cheese influences its textural characteristics (Metzger et al., 2001; Hassan et al., 2004). However, the importance of bound $P$, particularly organic $P$, in defining cheese characteristics has been studied to a lesser extent. Studies conducted on caseins have indicated that organic $\mathrm{P}$ is important for several functional interactions in food systems in which caseins are involved (Yamauchi and Yoneda, 1978; Van Hekken and Strange, 1993; Van Hekken et al., 1996). It appears that a hindrance in investigating the influence of organic $\mathrm{P}$ or bound $\mathrm{Ca}$ on cheese characteristics is the cumbersome analytical methods used for measuring these constituents in cheese.

In the absence of a method to measure organic $\mathrm{P}$ in cheese, a method was recently developed in our laboratory (see Materials and Methods) based on a previously 
suggested fractionation technique for measuring organic P in milk (Jenness and Patton, 1959). However, the method developed for cheese involves multiple extraction and ashing steps, and takes at least $2 \mathrm{~d}$ to analyze a sample. Therefore, a rapid and less cumbersome method would be valuable. In contrast, numerous techniques for measuring bound $\mathrm{Ca}$ in Cheddar cheese have been described in the past, but each method has its own limitations. Morris et al. (1988) suggested a method for determining bound Ca by extraction of the aqueous phase of cheese by pressing. In this method, the grated cheese is mixed with sand, packed in a perforated hoop, and pressed ( $32 \mathrm{MPa}$ ) at room temperature for $1 \mathrm{~h}$. The Ca content in the liquid that is extracted from the cheese is the soluble Ca content of cheese. Later, a water-extraction method, based on previous water-extraction methods (Sinha et al., 1979; Kimura et al., 1992), was developed and used to evaluate the bound and soluble Ca in Mozzarella cheese (Metzger et al., 2001). A more recently developed method uses acidbase buffering curves to measure the bound $\mathrm{Ca}$ in cheeses (Hassan et al., 2004). This method is based on the principle that bound $\mathrm{Ca}$ in cheese is related to its $\mathrm{pH}$ buffering peak at $\mathrm{pH}$ 5.0. The titration method proposed by Hassan et al. (2004) for bound Ca measurement also requires measurement of the $\mathrm{pH}$ buffering curve of the milk used for cheese manufacture. However, it may be possible to use only the buffering peak of the cheese and still obtain an accurate estimate of bound Ca. A common limitation with the analytical methods based on water extraction and acid-base buffer curves is that they are time consuming, and more importantly, involve dilution of the cheese. Dilution of the cheese can alter the distribution of $\mathrm{Ca}$, which would lead to erroneous results for bound Ca. Therefore, none of the methods developed to date has been universally accepted. The ability of the latter 2 methods to explain observed physicochemical phenomena in cheese indicates that they are related, although a study comparing the 2 methods for bound Ca has never been conducted. Nonetheless, a rapid method of analysis that does not involve dilution or numerous steps would be useful.

Graves and Luo (1994) used Fourier transform infrared (FTIR) spectroscopy to identify phosphates in proteins, and suggested that FTIR spectroscopy could be used to obtain information about the ionization state of phosphate esters and their binding with metal ions. Van Hekken and Dudley (1997) also used FTIR to study the covalently bound phosphate (i.e., organic P) in caseins. In a more recent study, Fernandez et al. (2003) used FTIR spectroscopy to unravel the changes in the interactions of phosphate ester bonds in a model $\alpha_{\mathrm{s}^{-}}$ casein system on precipitation by chitosan. They demonstrated that the dianionic symmetric stretching band of the covalently bound phosphate (organic P) in $\alpha_{\mathrm{s}^{-}}$ casein at $976 \mathrm{~cm}^{-1}$ is sensitive to changes in the ionization state of phosphate and electrostatic interactions with $\mathrm{Ca}$ ions. This study prompted us to investigate the possibility of utilizing the IR region of 1,050 to $900 \mathrm{~cm}^{-1}$, as identified by Fernandez et al. (2003), for measurement of organic $\mathrm{P}$ and bound $\mathrm{Ca}$ in cheese.

Infrared spectroscopy has been used for several decades to quantify fat, protein, and lactose in milk (Adda et al., 1968; Biggs, 1972). With the developments in spectroscopic instrumentation and computational ability to mathematically manipulate the spectra, FTIR spectroscopy has gained popularity for food analysis (van de Voort, 1992). Although FTIR spectroscopy offers a high signal-to-noise ratio and a significantly reduced scan time (Ingle and Crouch, 1988), it poses sample handling challenges (Chen and Irudayaraj, 1998), and complicated spectral analysis (van de Voort, 1992). Because of the texture and opacity of cheese, it is difficult to analyze cheese spectroscopically using a traditional transmission sample handling technique. Hence, the use of an attenuated total reflectance (ATR) sample handling technique is more appropriate for cheese samples. Use of ATR-FTIR requires minimal sample preparation; and variations in sample thickness do not affect the intensity of the bands (Ingle and Crouch, 1988). Fourier transform infrared spectra collected from a complex sample matrix like Cheddar cheese are difficult to interpret using simple linear regression models because the spectra may consist of broad overlapping bands of various other substances that are present. Additionally, the number of data points in the spectra necessitates use of multivariate statistical tools, such as partial least squares (PLS) regression, to extract relevant information from the spectral data (van de Voort, 1992). A large number of samples that cover a wide range in variability of the desired attribute will contribute to the robustness of the calibration model.

The objective of the present study was to determine if ATR-FTIR spectroscopy and available multivariate statistical tools could be used to measure organic $\mathrm{P}$ and bound $\mathrm{Ca}$ in cheese. Also, the relationship between bound Ca measured by a water-extraction method and the area of the $\mathrm{pH}$ buffering peak at $\mathrm{pH} \sim 5.1$ of cheese was assessed.

\section{MATERIALS AND METHODS}

\section{Experimental Design}

Cheese samples used in the study were obtained from 3 replicates of Cheddar cheeses that were manufactured with 2 levels (high and low) of $\mathrm{Ca}$ and $\mathrm{P}$, residual lactose, and salt-to-moisture ratio (S/M). The 8 different treatments included high $\mathrm{Ca}$ and P-high lactose-high 
S/M (HHH); high $\mathrm{Ca}$ and P-high lactose-low S/M (HHL); high $\mathrm{Ca}$ and P-low lactose-high S/M (HLH); high Ca and P-low lactose-low S/M (HLL); low Ca and P-high lactose-high S/M (LHH); low Ca and P-high lactose-low S/M (LHL); low Ca and P-low lactose-high S/ M (LLH); and low Ca and P-low lactose-low S/M (LLL). Treatments with a high level of $\mathrm{Ca}$ and $\mathrm{P}$ were produced by setting the milk and drawing the whey at a higher $\mathrm{pH}$ (6.6 and 6.3 respectively) compared with the treatments with a low level of $\mathrm{Ca}$ and $\mathrm{P}(\mathrm{pH}$ of 6.2 and 5.7 respectively). The lactose content in the cheeses was varied by adding lactose ( $2.5 \%$ by weight of milk) to the milk for high-lactose cheeses, and by washing the curd for low-lactose cheeses. The difference in S/M was obtained by dividing the curds into 2 halves, weighing each half, and salting at 3.5 and $2.25 \%$ of the weight of the curd for high and low S/M, respectively. A detailed description of the cheese manufacturing protocols followed to obtain the desired cheese composition is discussed elsewhere (Upreti and Metzger, 2006). The cheeses were ripened for $48 \mathrm{wk}$. Differences in lactose and S/M in cheeses influenced acid production during ripening, and in conjunction with $\mathrm{Ca}$ and $\mathrm{P}$, influenced the $\mathrm{pH}$ of the cheeses, which further influenced shifts between different forms of $\mathrm{Ca}$ and $\mathrm{P}$ in the cheeses. Changes in organic $\mathrm{P}$, bound $\mathrm{Ca}, \mathrm{pH}$ buffering curves, and FTIR spectra were measured during ripening ( $\mathrm{d} 1$, and wk $1,2,3,4$, $8,16,32$, and 48). The cheese $\mathrm{pH}$ buffering curves for the first $4 \mathrm{wk}$ of the first replication were measured with a different rate of titrant addition compared with the rest of the samples and were not used for the correlation analyses performed in this study. Hence, results of 216 samples were considered for organic P, bound $\mathrm{Ca}$, and FTIR spectra, whereas only 167 samples were considered for the cheese $\mathrm{pH}$ buffering curves.

\section{Organic $P$}

Approximately $1.5 \mathrm{~g}$ of ground cheese was transferred to a $45-\mathrm{mL}$ plastic vial (IEC autoclear polycarbon, Fisher Scientific, Fair Lawn, NJ) and $30 \mathrm{~mL}$ of $12 \%$ TCA was added. The cheese and 12\% TCA solution was blended with an Omni mixer-homogenizer (model 17105, Omni International, Waterbury, CT) at a setting of 3.5 for $30 \mathrm{~s}$ to extract the protein-bound colloidal calcium phosphate. The dispersion was then centrifuged (IEC HT centrifuge, International Equipment Company, Bedford, MA) at 7,000 $\times g$ for $10 \mathrm{~min}$. The supernatant was discarded and the pellet was reextracted using an additional $30 \mathrm{~mL}$ of $12 \%$-TCA. The fat adhering to the sides of the vial was removed using Kim wipes (Kimberly-Clark Corp., Roswell, GA) or cotton swabs (PSS Select cotton-tipped applicator, Jacksonville, FL). The pellet remaining after the second extrac- tion was transferred to a crucible and $1 \mathrm{~mL}$ of $1 \% \mathrm{CaCl}_{2}$ solution was added to the pellet. A glass rod was used to disperse the pellet, and additional volumes of deionizeddistilled water were added to the crucible to wash the glass rod. The contents of the crucible were then heated on a hot plate to remove the moisture. The dried pellet was then transferred to a muffle furnace (Thermolyne Sybron Corporation, Dubuque, IA) at $450^{\circ} \mathrm{C}$ for $3 \mathrm{~h}$. After $3 \mathrm{~h}$ of ashing, the crucible was allowed to cool, and $1 \mathrm{~mL}$ of concentrated nitric acid was added to wet the ash to facilitate complete ashing. The acid was evaporated on a hot plate, and the crucible was again transferred to the muffle furnace at $450^{\circ} \mathrm{C}$ for $3 \mathrm{~h}$. Additional nitric acid and heating at $450^{\circ} \mathrm{C}$ was repeated until a white ash (without black particles) was obtained.

After complete ashing, $1 \mathrm{~mL}$ of concentrated nitric acid was added to the crucible. The crucible was covered, and left undisturbed for complete solubilization of the ash. The contents of crucible were then transferred to a volumetric flask or a vial, and diluted to 35 $\mathrm{mL}$ using distilled water. Subsequent steps involve P analysis by colorimetry as recommended by AOAC (1995; method number 991.25).

\section{Bound Ca}

Bound Ca in cheese was measured using the method developed by Metzger et al. (2001). In this method, cheese is ground with warm water, filtered, and the calcium content of the filtrate is determined using atomic absorption spectroscopy. The amount of bound $\mathrm{Ca}$ in cheese is then determined by subtracting the soluble $\mathrm{Ca}$ from the total Ca content of the cheese.

\section{pH Buffering Curves}

The $\mathrm{pH}$ titration curves for the cheeses were obtained in duplicate by titrating a cheese:water $(1: 39 \mathrm{wt} / \mathrm{wt})$ dispersion with $1 \mathrm{~N} \mathrm{HCl}$ to $\mathrm{pH} 3.5$, and backtitrating with $1 \mathrm{~N} \mathrm{NaOH}$ to $\mathrm{pH}$ 8.5. The cheese-water dispersions were prepared by homogenizing $3 \mathrm{~g}$ of cheese with $17 \mathrm{~g}$ of water using a high-shear mixer-homogenizer (model 17105, Omni International) at a setting of 4 for $1 \mathrm{~min}$. To each cheese dispersion, $100 \mathrm{~mL}$ of water was then added to obtain a final cheese-water dispersion with a dilution factor of 1:39 (wt/wt). The titration curves obtained were converted to $\mathrm{pH}$ buffering curves (Figure 1). Additional details of this methodology have been previously reported (Upreti et al., 2006). The area of the buffering peak at $\mathrm{pH} 5.1$ was determined by integrating the area under the peak from the initial $\mathrm{pH}$ to $\mathrm{pH} 4.5$ (shown as the shaded area in Figure 1). 


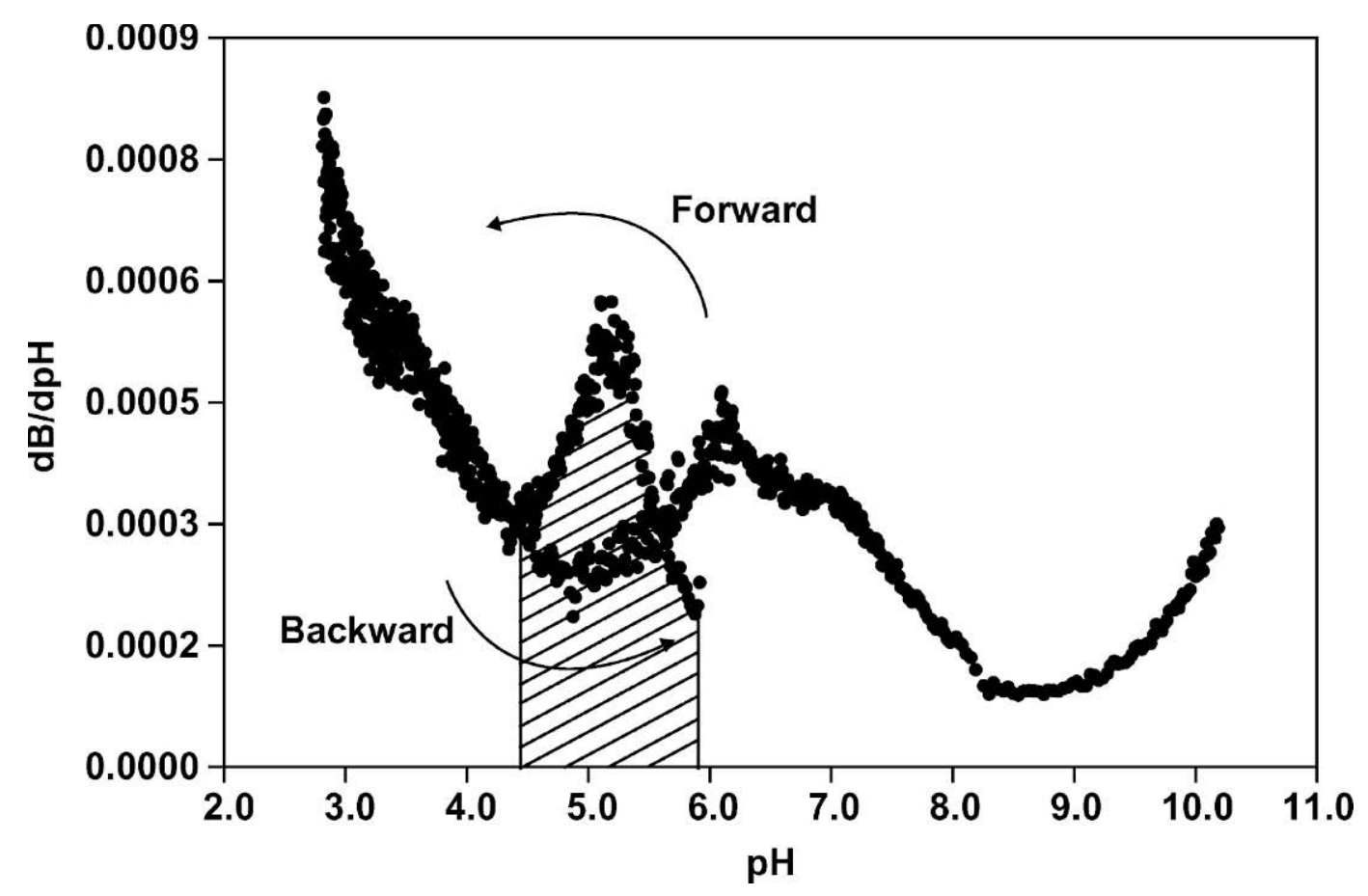

Figure 1. Typical buffering curve of a 1:39 (wt/wt) cheese:water dispersion (shown is the HLH treatment = high Ca and P, low lactose, and high S/M). The shaded area was used as the measure of buffering capacity of cheese.

\section{FTIR Spectroscopy}

A protocol for sampling cheese for FTIR spectroscopy was developed. Four slices (50 mm long $\times 50 \mathrm{~mm}$ wide $\times 5 \mathrm{~mm}$ thick) of cheese were obtained from the center of each block of cheese using a controlled thickness wire cutter. The cheese slices were then wrapped in Reynolds food service film (Alcoa Inc., Rogers, MN) to prevent moisture loss, and tempered to room temperature (about $20^{\circ} \mathrm{C}$ ). A Nicolet 560 FTIR spectrometer (Nicolet Instrument Corp., Madison, WI) with a flat ZnSe ATR crystal accessory (Thermo Spectra-Tech, Madison, WI) was used for collecting the infrared spectra. A background spectrum of the ZnSe crystal was recorded before the sample measurements were made. The sliced cheeses were then mounted on the flat ZnSe ATR crystal. Proper contact between the sample and the crystal was ensured using the pressure pad assembly in the instrument. The sample was left under these conditions for $5 \mathrm{~min}$ before the start of data collection. The spectrum was collected in the region between 4,000 and 650 $\mathrm{cm}^{-1}$ at a resolution of $4 \mathrm{~cm}^{-1}$, and 256 scans per sample using OMNIC software (OMNIC E.S.P., Nicolet Instrument Corp.). Four spectra were collected from 4 subsamples of each cheese at each time point.

\section{Mathematical Processing and Spectral Analysis}

The 4 spectra collected for each sample were averaged using OMNIC software (OMNIC E.S.P., Nicolet Instrument Corp.), and this averaged spectrum was subsequently used for additional mathematical processing (GRAMS 32AI, Galactic Industries Corp., Salem, NH). The spectral region of 1,050 to $900 \mathrm{~cm}^{-1}$, as suggested by Fernandez et al. (2003), was extracted from the complete IR spectrum for the quantification of organic $\mathrm{P}$, bound $\mathrm{Ca}$, and buffering capacity of cheeses. The extracted spectral region was mean centered and normalized to unit area to characterize the spectra for shifts rather than amplitude.

The preprocessed spectral data collected were analyzed using PLS regression analysis. Partial least squares regression is a multivariate statistical tool, and was used to build a linear model between the compositional data and spectral data. This technique evaluates the entire absorption spectrum and determines which portions of the spectrum are correlated to the attribute of interest (van de Voort, 1992). Three separate PLS regression models for organic $\mathrm{P}$, bound $\mathrm{Ca}$, and buffering peak area were developed by calculating PLS regression factors as linear combinations of the spectral variation. The PLS regression modeling was done using 
Table 1. Average chemical composition of cheeses expressed as percentage by weight of cheese (mean of 3 replicates)

\begin{tabular}{lcccccccc}
\hline & \multicolumn{7}{c}{ Treatments $^{1}$} \\
\cline { 2 - 8 } & HHH & HHL & HLH & HLL & LHH & LHL & LLH & LLL \\
\hline Moisture & $32.07^{\mathrm{a}}$ & $33.80^{\mathrm{bc}}$ & $33.07^{\mathrm{ab}}$ & $35.21^{\mathrm{de}}$ & $34.08^{\mathrm{bcd}}$ & $35.94^{\mathrm{e}}$ & $34.39^{\mathrm{cd}}$ & $37.57^{\mathrm{f}}$ \\
Fat & $35.93^{\mathrm{a}}$ & $34.95^{\mathrm{ab}}$ & $35.66^{\mathrm{ab}}$ & $34.75^{\mathrm{abc}}$ & $34.48^{\mathrm{bcd}}$ & $33.62^{\mathrm{cd}}$ & $34.67^{\mathrm{abc}}$ & $33.32^{\mathrm{d}}$ \\
Protein & $26.40^{\mathrm{a}}$ & $25.55^{\mathrm{abc}}$ & $26.02^{\mathrm{ab}}$ & $25.29^{\mathrm{bcd}}$ & $25.15^{\mathrm{cd}}$ & $24.77^{\mathrm{cd}}$ & $25.29^{\mathrm{bcd}}$ & $24.46^{\mathrm{d}}$ \\
Salt & $2.04^{\mathrm{bc}}$ & $1.68^{\mathrm{d}}$ & $2.14^{\mathrm{ab}}$ & $1.73^{\mathrm{cd}}$ & $2.28^{\mathrm{ab}}$ & $1.63^{\mathrm{d}}$ & $2.47^{\mathrm{a}}$ & $1.75^{\mathrm{cd}}$ \\
Salt-to-moisture ratio & $6.37^{\mathrm{a}}$ & $4.98^{\mathrm{b}}$ & $6.48^{\mathrm{a}}$ & $4.92^{\mathrm{b}}$ & $6.71^{\mathrm{a}}$ & $4.53^{\mathrm{b}}$ & $7.17^{\mathrm{a}}$ & $4.65^{\mathrm{b}}$ \\
Lactose (d 1) & $1.52^{\mathrm{a}}$ & $1.35^{\mathrm{c}}$ & $0.32^{\mathrm{de}}$ & $0.11^{\mathrm{e}}$ & $1.64^{\mathrm{ab}}$ & $1.41^{\mathrm{bc}}$ & $0.49^{\mathrm{d}}$ & $0.27^{\mathrm{e}}$ \\
Total Ca & $0.69^{\mathrm{a}}$ & $0.68^{\mathrm{a}}$ & $0.67^{\mathrm{a}}$ & $0.66^{\mathrm{a}}$ & $0.55^{\mathrm{b}}$ & $0.54^{\mathrm{b}}$ & $0.55^{\mathrm{b}}$ & $0.51^{\mathrm{b}}$ \\
Total P & $0.48^{\mathrm{a}}$ & $0.48^{\mathrm{a}}$ & $0.48^{\mathrm{a}}$ & $0.47^{\mathrm{a}}$ & $0.42^{\mathrm{b}}$ & $0.42^{\mathrm{b}}$ & $0.41^{\mathrm{b}}$ & $0.40^{\mathrm{b}}$ \\
\hline
\end{tabular}

${ }^{\mathrm{a}-\mathrm{f}}$ Means in a row with common superscript do not differ $(P \geq 0.05)$.

${ }^{1}$ Treatments: $\mathrm{HHH}=$ high $\mathrm{Ca}$ and $\mathrm{P}$, high lactose, and high $\mathrm{S} / \mathrm{M} ; \mathrm{HHL}=$ high $\mathrm{Ca}$ and $\mathrm{P}$, high lactose, and low S/M; HLH = high Ca and P, low lactose, and high S/M; HLL = high Ca and P, low lactose, and low $\mathrm{S} / \mathrm{M} ; \mathrm{LHH}=$ low $\mathrm{Ca}$ and $\mathrm{P}$, high lactose, and high $\mathrm{S} / \mathrm{M} ; \mathrm{LHL}=$ low $\mathrm{Ca}$ and $\mathrm{P}$, high lactose, and low $\mathrm{S} / \mathrm{M}$; $\mathrm{LLH}=$ low $\mathrm{Ca}$ and $\mathrm{P}$, low lactose, and high S/M; LLL = low Ca and P, low lactose, and low S/M.

a leave-one-out cross-validation method in which 216 submodels (unless otherwise stated) were built leaving each sample out once, and a full model with all the samples. The relevant number of PLS factors used in the model was determined by plotting the prediction residual error sum squares (PRESS) vs. the number of PLS factors, such that the lowest PRESS value was obtained using the least number of factors. Subsequently, samples that had large studentized $t$-residuals were identified as outliers and were eliminated from the training set. A final prediction model was then developed using the remaining samples, considering the same methodology described above.

\section{RESULTS AND DISCUSSION}

The mean composition of the 8 Cheddar cheeses is shown in Table 1 . The differences in total $\mathrm{Ca}, \mathrm{P}$, residual lactose, and $\mathrm{S} / \mathrm{M}$ in the cheeses led to differences in acid production, $\mathrm{pH}$ changes, solubilization of $\mathrm{Ca}$, proteolysis, and dephosphorylation during ripening. Consequently, the data set used for spectral comparisons consisted of samples that had a wide range of organic $\mathrm{P}$, bound $\mathrm{Ca}$, and buffering capacities (Table 2). The range of these concentrations encompasses concentrations of the respective constituents that are typically found in Cheddar cheeses.

\section{Comparison of Bound Ca vs. Buffering Peak Area}

In the absence of a study that related the values of bound $\mathrm{Ca}$ as estimated by water-extraction method (Metzger et al., 2001) to the area of the buffering peak at $\mathrm{pH}$ 5.1, a regression analysis was performed between measured concentrations of bound $\mathrm{Ca}$ and cheese buffering peak areas. Regression analysis between the area of the $\mathrm{pH}$ buffering peak at $\mathrm{pH} 5.1$ (shaded region in Figure 1) and bound $\mathrm{Ca}$ measured using the waterextraction method shows good correlation $\left(R^{2}=0.73\right)$. As shown in Figure 2, an increase in bound Ca corresponded to an increase in buffering peak area at pH 5.1. However, bound $\mathrm{Ca}$ alone does not account for the total buffering peak area, and a portion is due to the protonation/deprotonation of the side chains of protein-bound amino acids in cheese. In our previous research, the contribution of protein-bound amino acids to the buffering peak area was determined by calculating the area under the curve between $\mathrm{pH} 4.5$ and 5.5, when the cheese-water dispersion at pH 3.5 or lower was backtitrated using an alkali (Upreti et al., 2006). Consequently, it is possible to correct for the buffering contribution of protein bound amino acids by subtracting the area under the curve that was related to protein-bound amino acids from the total buffering peak area. This analysis was performed and the corrected peak area

Table 2. Summary of samples used for developing the calibration and statistical analysis

\begin{tabular}{llllll}
\hline & $\begin{array}{l}\text { No. of } \\
\text { samples }\end{array}$ & Range & $\begin{array}{l}\text { Correlation } \\
\text { of prediction }\end{array}$ & $\begin{array}{l}\text { Factors for } \\
\text { prediction }\end{array}$ & $\begin{array}{l}\text { Outliers } \\
\text { deleted }\end{array}$ \\
\hline Organic P, \% & 216 & $0.09-0.20$ & 0.76 & 2 & - \\
Bound Ca, \% & 216 & $0.05-0.42$ & 0.70 & 5 & 1 \\
Buffering peak area & 167 & $0.0007-0.0049$ & 0.64 & 5 & - \\
\hline
\end{tabular}




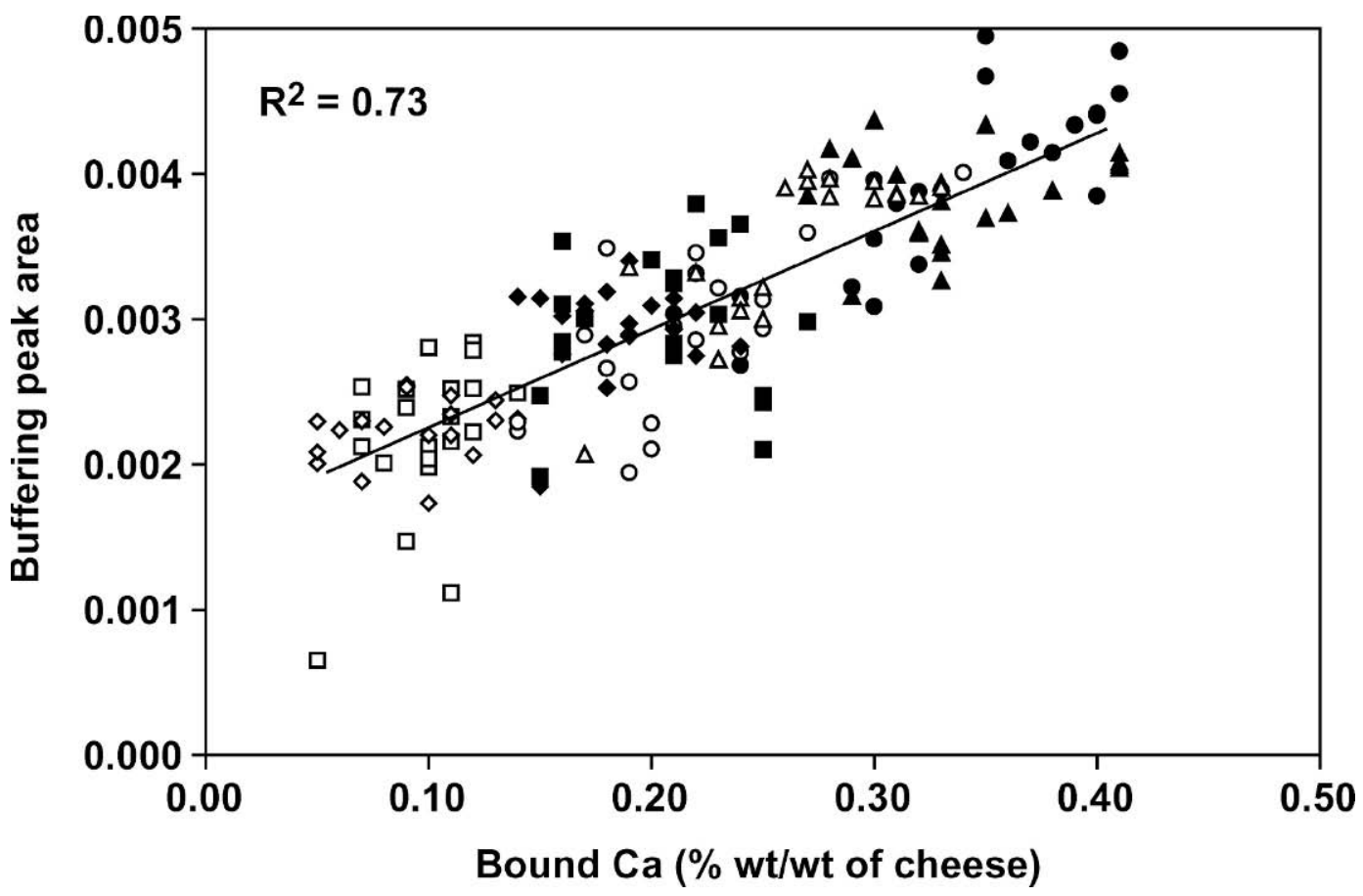

Figure 2. Correlation between bound Ca and buffering peak area $(\mathrm{n}=167)$. HHH $(-)=$ high $\mathrm{Ca}$ and $\mathrm{P}$, high lactose, and high S/M; HHL $(\mathrm{O})=$ high $\mathrm{Ca}$ and $\mathrm{P}$, high lactose, and low S/M; HLH $(\boldsymbol{\Delta})=$ high Ca and P, low lactose, and high S/M; HLL $(\triangle)=$ high Ca and P, low lactose, and low S/M; LHH $(\square)=$ low Ca and P, high lactose, and high S/M; LHL $(\square)=$ low Ca and P, high lactose, and low S/M; LLH $(\bullet)=$ low Ca and $\mathrm{P}$, low lactose, and high S/M; LLL $(\diamond)=$ low Ca and P, low lactose, and low S/M.

was then compared with the concentration of bound $\mathrm{Ca}$ in the cheeses. Regression analysis found a good correlation between the corrected peak area and bound $\mathrm{Ca}$ in the cheese $\left(\mathrm{R}^{2}=0.72\right)$. Before conducting this analysis, we had expected higher correlation between the bound $\mathrm{Ca}$ and the corrected peak area compared with the total peak area. The similar correlations obtained with the corrected and total peak area might be because all of the cheeses had similar protein content and thus, the contribution of protein-bound amino acid to the total peak area may have been similar in all cheeses. Nonetheless, our results indicate that the bound $\mathrm{Ca}$ measured by the water-extraction method and buffering peak area at $\mathrm{pH} 5.1$ are correlated. However, both of these methods (water extraction and $\mathrm{pH}$ buffering curves) for measuring bound Ca involve dilution of the cheese. Therefore, FTIR spectroscopy as a technique to measure bound $\mathrm{Ca}$ was assessed because of its ability to measure bound Ca without any sample dilution.

\section{Interpretation of the FTIR Spectra}

As suggested by Fernandez et al. (2003), a spectral region from 1,050 to $900 \mathrm{~cm}^{-1}$ was considered in our study. Figure 3 shows the unit area normalized spectra for treatments $\mathrm{HHH}$ at $\mathrm{d} 1$ and LLL at 12 mo. Spectra of these 2 samples were presented because they had the largest difference in bound $\mathrm{Ca}$ and organic $\mathrm{P}(0.39$ and $0.19 \%$ for $\mathrm{HHH}$, and 0.05 and $0.10 \%$ for LLL, respectively). The dianionic stretching band of the organic $P$ in our spectra had a maximum at $965 \mathrm{~cm}^{-1}$, as opposed to $976 \mathrm{~cm}^{-1}$ suggested by Fernandez et al. (2003). This might be because the sample used in our study was Cheddar cheese compared with the pure $\alpha_{\mathrm{s}}$-casein used by Fernandez et al. (2003). It is possible that the presence of numerous constituents in cheese may have led to shifts in the absorbance maximum. As is apparent from Figure 3, the spectra for the 2 cheese samples look different, but it is difficult to quantify these differences unless multivariate statistical tools, such as PLS, are used.

\section{PLS Analysis for Prediction of Organic P}

Partial least squares regression analysis between the measured organic P content and the FTIR spectra for all 216 samples was performed. The PRESS plot generated by the PLS regression analysis indicated that 2 factors were required for developing the calibration 


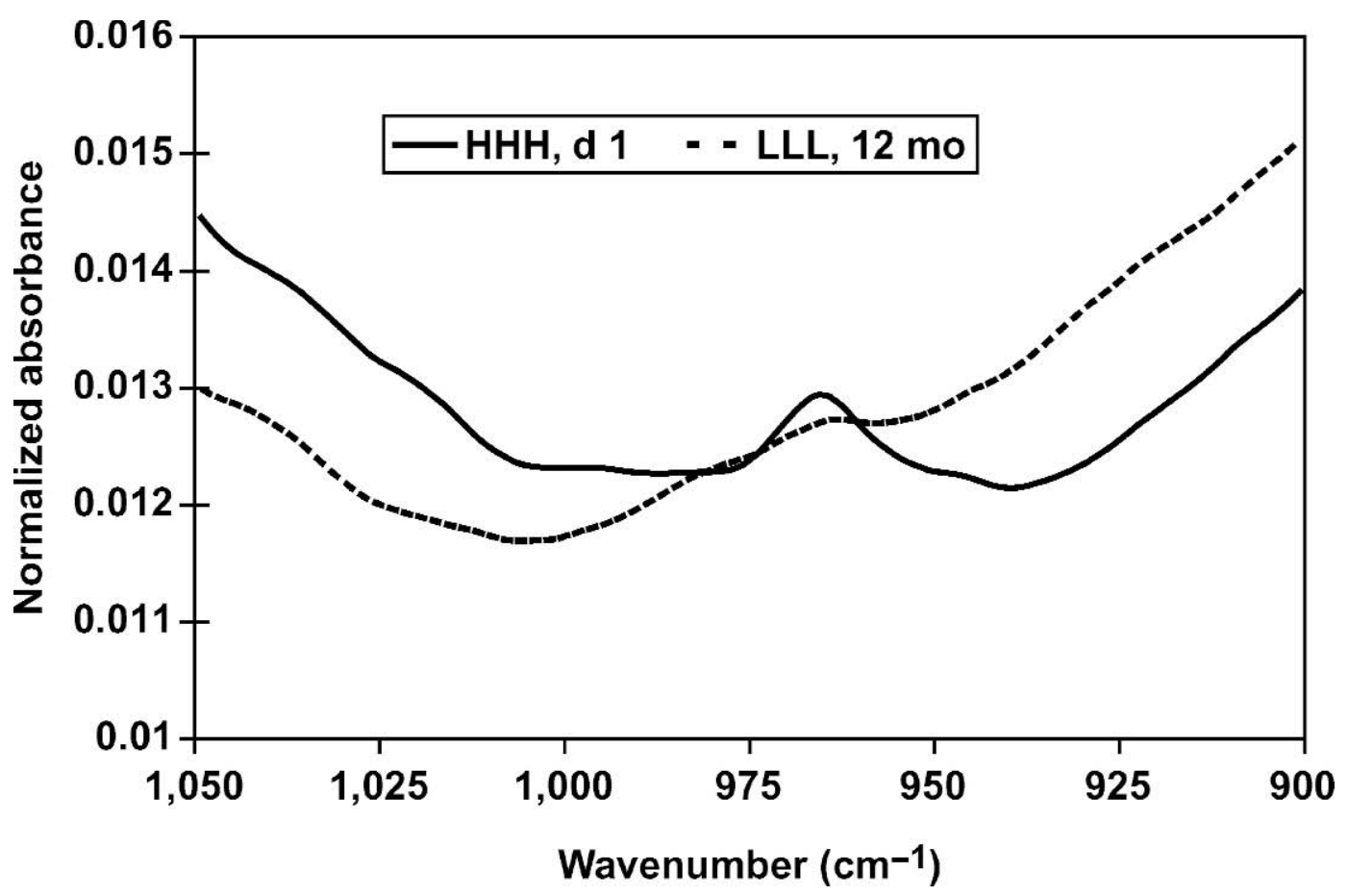

Figure 3. Unit area normalized infrared spectra used for characterizing the shifts. $\mathrm{HHH}=$ high Ca and $\mathrm{P}$, high lactose, and high $\mathrm{S} / \mathrm{M}$; $\mathrm{LLL}=$ low $\mathrm{Ca}$ and $\mathrm{P}$, low lactose, and low $\mathrm{S} / \mathrm{M}$.

model for organic $\mathrm{P}$ in the cheeses. A plot of correlation coefficients for each wavelength in the spectra with the organic $\mathrm{P}$ values is shown in Figure 4a. Although the entire spectrum was collected, the spectral region from 956 to $946 \mathrm{~cm}^{-1}$ had the highest correlation with the measured organic $\mathrm{P}$ content. A predictive model using the 2 factors was generated, and the respective plot of predicted vs. measured organic $\mathrm{P}$ content is shown in Figure 4b. The data points in the plot have been identified by their respective treatments to identify any potential biases in the regression analysis because of the treatment effects. As is apparent from Figure 4 , the model performs better in the concentration range of 0.12 to $0.2 \%$; however, it overpredicts at concentrations below $0.12 \%$. The inability of the model to satisfactorily predict at low concentrations may be related to insignificant shifts in the spectra due to low IR absorbance at lower concentrations of organic P. Nonetheless, a correlation coefficient $\left(\mathrm{R}^{2}\right)$ of 0.76 indicates that FTIR is suitable for predicting the organic $\mathrm{P}$ concentration of cheese.

\section{PLS Analysis for Prediction of Bound Ca}

Partial least squares regression analysis between the measured concentrations of bound $\mathrm{Ca}$ and the FTIR spectra for the 216 samples was performed. The PRESS plot generated by PLS regression analysis indicated that 5 factors were required for developing the calibration model for bound $\mathrm{Ca}$ in cheeses. In addition, results for studentized $t$-residuals indicated that one sample was an outlier; this sample was eliminated from the data set that was used for developing the final prediction model.

A plot of the correlation coefficients for each wavelength in the spectra with the bound Ca values is shown in Figure 5a. This plot indicates that the spectral region $\sim 980 \mathrm{~cm}^{-1}$ had the highest correlation with the measured concentrations of bound $\mathrm{Ca}$ in cheese compared with 956 to $946 \mathrm{~cm}^{-1}$ for organic $P$. This difference in the spectral region with the highest correlation for bound calcium may be explained by the fact that a shift in the phosphate peak maxima toward higher wavenumbers occurs when it interacts with Ca ions (Fernandez et al., 2003). Subsequently, a predictive model using the 5 factors was developed, and the respective plot of predicted vs. measured bound Ca concentrations of the samples is shown in Figure 5b. As apparent from the figure, there is some variability in the prediction. This variability may be due to various factors including possible variability in the results for the chemical method or spectral shifts that are related to factors other than Ca binding to organic phosphates. However, the correlation coefficient $\left(R^{2}\right)$ of 0.70 obtained indicates that FTIR may be applicable for predicting the bound Ca concentration of cheese. Still, further research is warranted 

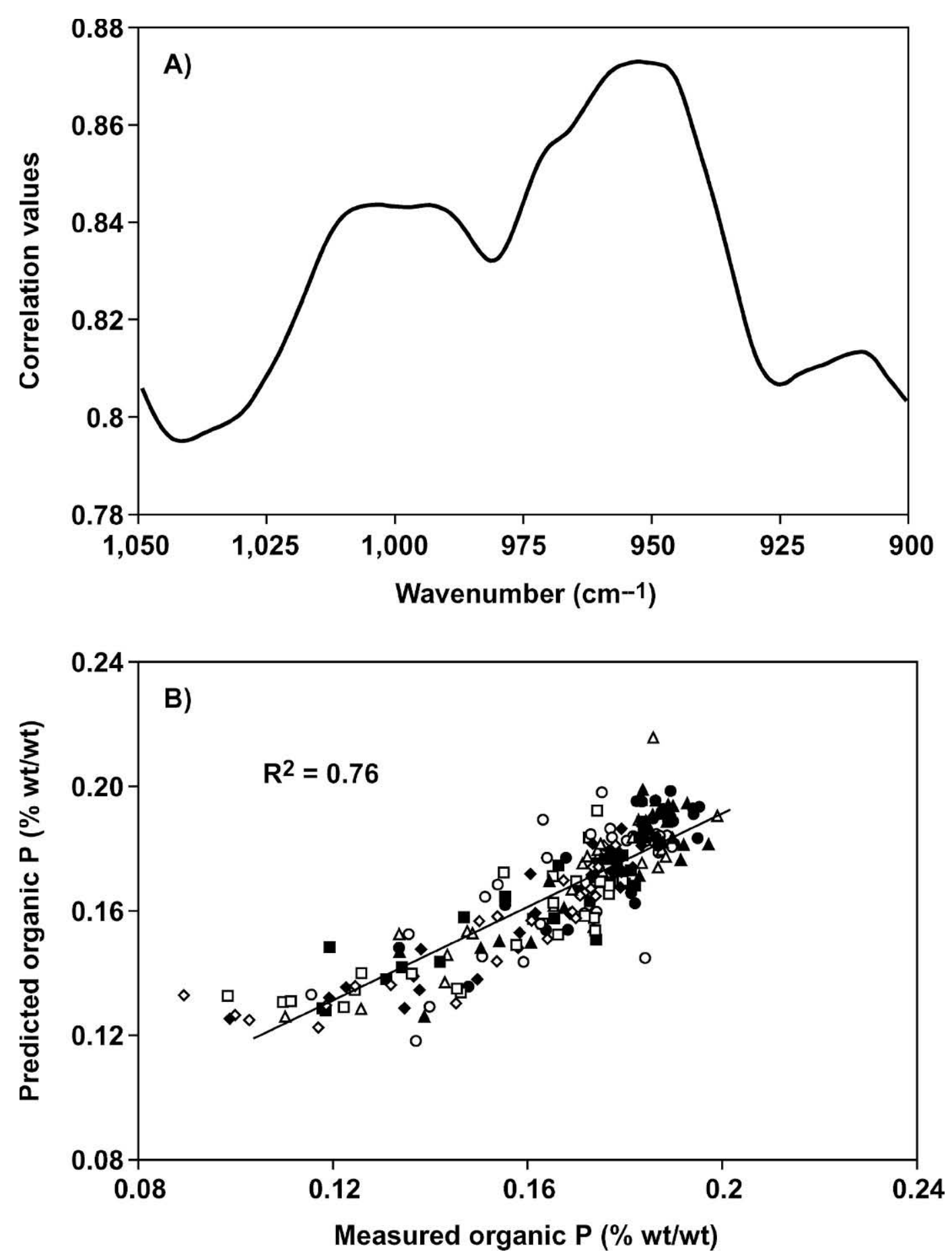

Figure 4. A) Correlation coefficient (R) of different wavenumbers in the IR spectra with organic P values; B) corresponding partial least squares prediction model $(\mathrm{n}=216)$. HHH $(\bullet)=$ high Ca and $\mathrm{P}$, high lactose, and high $\mathrm{S} / \mathrm{M} ; \mathrm{HHL}(\mathrm{O})=$ high Ca and $\mathrm{P}$, high lactose, and low S/M; HLH $(\mathbf{\Delta})=$ high Ca and P, low lactose, and high S/M; HLL $(\triangle)=$ high Ca and P, low lactose, and low S/M; LHH $(\square)=$ low Ca and P, high lactose, and high S/M; LHL $(\square)=$ low Ca and P, high lactose, and low S/M; LLH $(\bullet)=$ low Ca and P, low lactose, and high S/M; LLL $(\diamond)=$ low Ca and P, low lactose, and low S/M. 

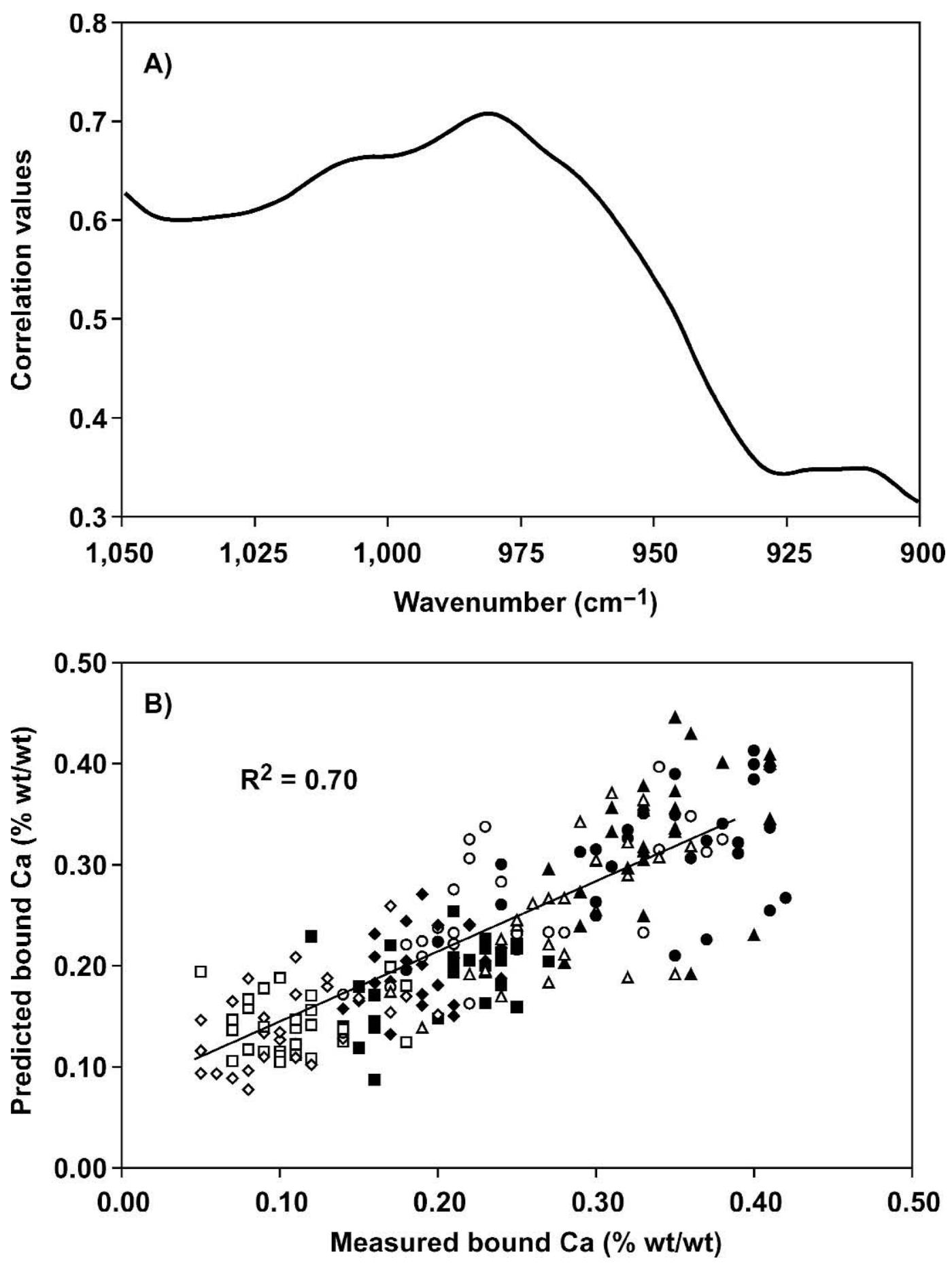

Figure 5. A) Correlation coefficient (R) of different wavenumbers in the IR spectra with bound Ca values; B) corresponding partial least squares prediction model $(\mathrm{n}=215)$. HHH $(\bullet)=$ high $\mathrm{Ca}$ and $\mathrm{P}$, high lactose, and high $\mathrm{S} / \mathrm{M} ; \mathrm{HHL}(\mathrm{O})=$ high $\mathrm{Ca}$ and $\mathrm{P}$, high lactose, and low S/M; HLH $(\mathbf{\Delta})=$ high Ca and P, low lactose, and high S/M; HLL $(\triangle)=$ high Ca and P, low lactose, and low S/M; LHH $(\square)=$ low Ca and P, high lactose, and high S/M; LHL $(\square)=$ low Ca and P, high lactose, and low S/M; LLH $(\diamond)$ = low Ca and P, low lactose, and high S/M; LLL $(\diamond)=$ low Ca and P, low lactose, and low S/M. 

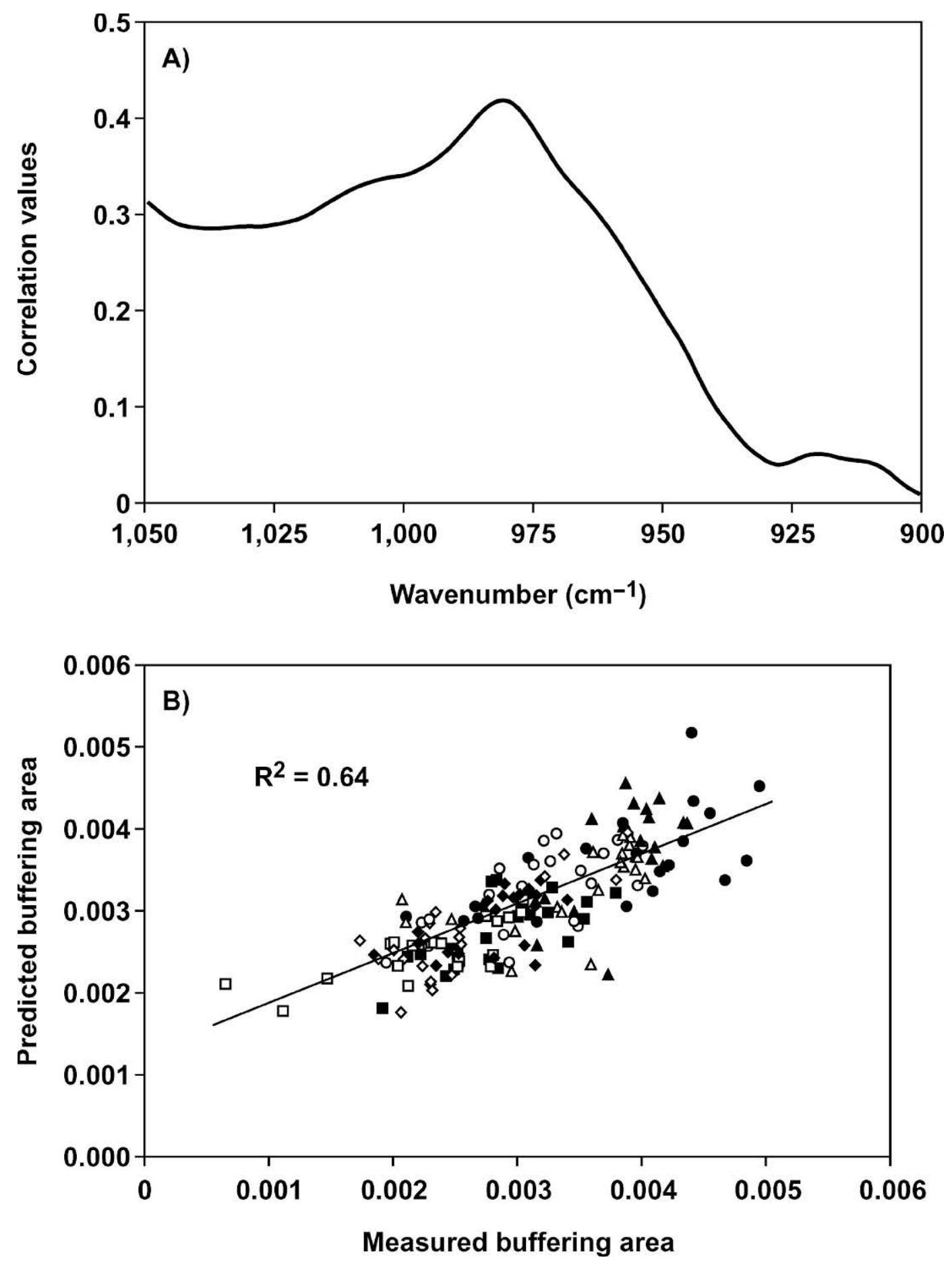

Figure 6. A) Correlation coefficient (R) of different wavenumbers in the IR spectra with buffering peak areas; B) corresponding partial least squares prediction model $(\mathrm{n}=167)$. HHH $(\bullet)=$ high Ca and P, high lactose, and high S/M; HHL $(O)=$ high Ca and P, high lactose, and low S/M; HLH $(\mathbf{\Delta})=$ high $\mathrm{Ca}$ and $\mathrm{P}$, low lactose, and high S/M; HLL $(\triangle)=$ high Ca and P, low lactose, and low S/M; LHH $(\mathbf{\square})=$ low $\mathrm{Ca}$ and $\mathrm{P}$, high lactose, and high S/M; LHL $(\square)=$ low Ca and P, high lactose, and low S/M; LLH $(\bullet)=$ low Ca and P, low lactose, and high $\mathrm{S} / \mathrm{M} ; \mathrm{LLL}(\diamond)=$ low $\mathrm{Ca}$ and $\mathrm{P}$, low lactose, and low S/M. 
to decrease the variability in the prediction, before this technique can be used as an alternative to other techniques.

\section{PLS Analysis for Prediction of Buffering Capacity of Cheese}

Because the level of bound calcium is related to cheese buffering capacity (Figure 2), it may be possible to predict cheese buffering capacity from the 1,050 to $900 \mathrm{~cm}^{-1}$ FTIR spectral region. Use of the FTIR spectra for measurement of buffering capacity would be valuable since the titration method is cumbersome and time consuming. Consequently, a PLS regression analysis between the measured buffering peak areas (shaded region in Figure 1) and the FTIR spectra for 167 samples was performed. The PRESS plot generated indicated that 5 factors were required for developing the calibration model for buffering capacity of the cheeses. A plot of the correlation coefficients for each wavelength in the spectra with the buffering peak areas is shown in Figure 6a. This plot indicates that the spectral region $\sim 980 \mathrm{~cm}^{-1}$ was correlated with the measured buffering capacity of the cheese. The fact that the same spectral region was correlated with both bound $\mathrm{Ca}$ and buffering peak areas supports previous research that bound $\mathrm{Ca}$ has a role in the buffering capacity of cheese (Hassan et al., 2004; Upreti et al., 2006).

A predictive model using the 5 factors was generated, and the respective plot of predicted vs. measured organic $\mathrm{P}$ concentration of the samples is shown in Figure $6 \mathrm{~b}$. As is apparent from the figure, the spectral data were moderately correlated with the buffering capacity of the cheese. This moderate correlation $\left(\mathrm{R}^{2}=0.64\right)$ indicates that a fraction of total area under the $\mathrm{pH}$ buffering peak is contributed by other constituents of cheese (Upreti et al., 2006). Consequently, an improved correlation may be possible if other regions of IR spectrum that account for protein-bound glutamate residues with minimal overlapping bands from other species can be identified and utilized in the prediction model.

\section{CONCLUSIONS}

Our results demonstrate that shifts in the FTIR spectral region from 1,050 to $900 \mathrm{~cm}^{-1}$ correlate with the measured concentrations of organic $\mathrm{P}$, bound $\mathrm{Ca}$, and the buffering capacity of cheese. Identification of other IR frequencies that show minimal overlapping absorbance bands from other chemical species, or use of mathematical transformations of the spectral data (such as derivatization) may aid in more robust predictions and should be evaluated in future studies. None- theless, FTIR spectroscopy has a potential to be used as a technique for measuring the organic $\mathrm{P}$, bound calcium, and buffering capacity of cheese and could replace existing methods which are difficult and time consuming to perform.

\section{ACKNOWLEDGMENTS}

We thank Dairy Management Inc. (Rosemont, IL), and Midwest Dairy Association (St. Paul, MN) for funding this project.

\section{REFERENCES}

Adda, J., E. Blanc-Patin, R. Jeunet, R. Grappin, G. Mocquot, B. Pousardieu, and G. Ricordeau. 1968. Essais d'utilisation de l'infra red milk analyzer. Lait 48:145-154.

AOAC. 1995. Official Methods of Analysis. 16th ed. Association of Official Analytical Chemists International, Arlington, VA.

Aoki, T., N. Yamada, I. Tomota, Y. Kako, and T. Imamura. 1987. Caseins are cross-linked by their ester phosphate groups by colloidal calcium phosphate. Biochim. Biophys. Acta 911:238-243.

Biggs, D. A. 1972. Infrared milk analyzer. J. Dairy Sci. 55:650-655.

Chen, M., and J. Irudayaraj. 1998. Sampling technique for cheese analysis by FTIR spectroscopy. J. Food Sci. 63:96-99.

Fernandez, C., S. F. Ausar, R. G. Badini, L. F. Castagna, I. D. Bianco, and D. M. Beltramo. 2003. An FTIR spectroscopy study of the interaction between $\alpha$ s-casein-bound phosphosyryl groups and chitosan. Int. Dairy J. 13:897-901.

Geurts, T. J., P. Walstra, and H. Mulder. 1972. Brine composition and the prevention of the defect "soft rind" in cheese. Neth. Milk Dairy J. 26:168-179.

Graves, D. J., and S. Luo. 1994. Use of photoacoustic Fourier-transform infrared spectroscopy to study phosphates in proteins. Biochem. Biophys. Res. Commun. 205:618-624.

Hassan, A., M. E. Johnson, and J. A. Lucey. 2004. Changes in the proportions of soluble and insoluble calcium during the ripening of Cheddar cheese. J. Dairy Sci. 87:854-862.

Ingle, J. D., and S. R. Crouch. 1988. Infrared spectroscopy. Pages 404-436 in Spectrochemical Analysis. Prentice Hall Inc., Upper Saddle River, NJ.

Jenness, R., and S. Patton. 1959. Milk salts. Pages 158-181 in Principles of Dairy Chemistry. John Wiley and Sons, Inc., New York, NY.

Kimura, T., Y. Sagara, M. Fukushima, and S. Taneya. 1992. Effect of $\mathrm{pH}$ on submicroscopic structure of string cheese. Milchwissenschaft 47:547-552.

Lawrence, R. C., H. A. Heap, and J. Gilles. 1984. A controlled approach to cheese technology. J. Dairy Sci. 67:1632-1645.

Lucey, J. A., and P. F. Fox. 1993. Importance of calcium and phosphate in cheese manufacture: A review. J. Dairy Sci. 76:1714-1724.

Metzger, L. E., D. M. Barbano, and P. S. Kindstedt. 2001. Effect of milk preacidification on low fat Mozzarella cheese: III. Post-melt chewiness and whiteness. J. Dairy Sci. 84:1357-1366.

Morris, H. A., C. Holt, B. E. Brooker, J. M. Banks, and W. Manson. 1988. Inorganic constituents of cheese: Analysis of juice from one-month-old Cheddar cheese and the use of light and electron microscopy to characterize the crystalline phases. J. Dairy Res. 55:255-268.

Pastorino, A. J., N. P. Ricks, C. L. Hansen, and D. J. McMahon. 2003. Effect of calcium and water injection on structure-function relationships of cheese. J. Dairy Sci. 86:105-113.

Schmidt, D. G. 1980. Colloidal aspects of casein. Neth. Milk Dairy J. 34:42-64.

Sinha, D. K., K. M. Shahani, A. Kilara, and R. M. Hill. 1979. Calcium, magnesium and phosphorus contents of cultured and acidified cottage cheese. Cult. Dairy Prod. J. 14:21-23. 
Upreti, P., P. Bühlmann, and L. E. Metzger. 2006. Influence of calcium and phosphorus, lactose, and salt-to-moisture ratio on Cheddar cheese quality: $\mathrm{pH}$ buffering properties of cheese. J. Dairy Sci. 89:938-950.

Upreti, P., and L. E. Metzger. 2006. Influence of calcium and phosphorus, lactose, and salt-to-moisture ratio on Cheddar cheese quality: Manufacture and composition. J. Dairy Sci. 89:420-428.

van de Voort, F. R. 1992. Fourier transform infrared spectroscopy applied to food analysis. Food Res. Int. 25:397-403.

Van Hekken, D. L., and R. L. Dudley. 1997. Analysis of modified whole casein with different phosphorus contents using phosphorus-31 nuclear magnetic resonance and Fourier transform infrared spectroscopy. J. Dairy Sci. 80:2751-2759.

Van Hekken, D. L., and E. D. Strange. 1993. Functional properties of dephosphorylated bovine whole casein. J. Dairy Sci. 76:3384-3391.

Van Hekken, D. L., E. D. Strange, and D. P. Lu. 1996. Functional properties of chemically phosphorylated whole casein. J. Dairy Sci. 79:1942-1949.

Yamauchi, K., and Y. Yoneda. 1978. Effect of dephosphorylation of casein on its coagulation and proteolysis by chymosin. Agric. Biol. Chem. 42:1031-1035. 